ISSN 2072-4292

www.mdpi.com/journal/remotesensing

Review

\title{
Supporting Global Environmental Change Research: A Review of Trends and Knowledge Gaps in Urban Remote Sensing
}

Elizabeth A. Wentz ${ }^{1}{ }^{*}$, Sharolyn Anderson ${ }^{2}$, Michail Fragkias ${ }^{3}$, Maik Netzband ${ }^{4}$, Victor Mesev ${ }^{5}$, Soe W. Myint ${ }^{1}$, Dale Quattrochi ${ }^{6}$, Atiqur Rahman ${ }^{7}$ and Karen C. Seto ${ }^{8}$

1 School of Geographical Sciences and Urban Planning, Arizona State University, Coor Hall, 5th Floor, 975 S. Myrtle Ave., Tempe, AZ 85287, USA

2 School of Natural and Built Environments, University of South Australia, Mawson Lakes Campus, Adelaide, SA 5001, Australia; E-Mail: Sharolyn.Anderson@unisa.edu.au

3 Department of Economics, College of Business and Economics (COBE), Boise State University, 1910 University, Boise, ID 83725, USA; E-Mail: michailfragkias@boisestate.edu

4 Department of Geography, Ruhr-University Bochum, Universitaetsstrasse 150, 44801 Bochum, Germany; E-Mail: maik.netzband@ rub.de

5 Department of Geography, Florida State University, 323 Bellamy Building, 113 Collegiate Loop, Tallahassee, FL 32306, USA; E-Mail: vmesev@fsu.edu

6 Earth Science Office, NASA Marshall Space Flight Center, Huntsville, AL 35812, USA;

E-Mail: dale.quattrochi@nasa.gov

7 Department of Geography, Jamia Millia Islamia University, New Delhi 110 025, India;

E-Mail: ateeqgeog@yahoo.co.in

8 Yale School of Forestry \& Environmental Studies, Yale University, 195 Prospect Street, New Haven, CT 06511, USA; E-Mail: karen.seto@yale.edu

* Author to whom correspondence should be addressed; E-Mail: wentz@asu.edu; Tel.: +1-480-965-7533; Fax: +1-480-965-8313.

Received: 11 November 2013; in revised form: 18 March 2014 / Accepted: 20 March 2014 / Published: 30 April 2014

Abstract: This paper reviews how remotely sensed data have been used to understand the impact of urbanization on global environmental change. We describe how these studies can support the policy and science communities' increasing need for detailed and up-to-date information on the multiple dimensions of cities, including their social, biological, physical, and infrastructural characteristics. Because the interactions between urban and surrounding areas are complex, a synoptic and spatial view offered from remote sensing is integral to measuring, modeling, and understanding these relationships. Here we focus on 
three themes in urban remote sensing science: mapping, indices, and modeling. For mapping we describe the data sources, methods, and limitations of mapping urban boundaries, land use and land cover, population, temperature, and air quality. Second, we described how spectral information is manipulated to create comparative biophysical, social, and spatial indices of the urban environment. Finally, we focus how the mapped information and indices are used as inputs or parameters in models that measure changes in climate, hydrology, land use, and economics.

Keywords: urban mapping; environmental indices; social indices; climate modeling; socioeconomic modeling

\section{Introduction}

Urbanization contributes to global environmental change in numerous ways and across multiple dimensions. Remote sensing can play a key role in providing information on urbanization to help science and policymaking. A key feature to understanding this urbanization process is monitored information on social, biological, and physical conditions of existing and transformed urban areas. Demographic and economic information are typically acquired through population censuses, surveys, and ethnographic studies performed nationally or locally. Information on the biological and physical dimensions of urban areas, such as the built environment and the urban land cover, is often more difficult to obtain. Furthermore, linkages between the social, biological, and physical characteristics are rarely developed because data streams are imperfectly coupled due to poor correspondence between temporal scales (data collection intervals) and spatial scales (administrative units and landscape units).

This scarcity of information comes at a time when the expectations from the policy and research communities require linked information to understand the local environmental impacts of urbanization (e.g., urban heat island or air quality), global environmental change due to urbanization (e.g., climate change), and the impacts of urban living on human well-being (e.g., health and economic outcomes). Recent calls for an "urbanization science" emphasize the need for new directions in data collection and analysis [1]. Remote sensing scientists are beginning to respond to a call to fulfill this unmet need for linked environmental and socio-economic information through remotely sensed data and methods [2].

The goal of this paper is to synthesize the current state of urban remote sensing science and assess how it can support the growing demand for information about the urbanization process and cities as places. We differentiate our review from others urban remote sensing reviews (see [3,4]) by focusing on how remote sensing can support global environmental change research and policy formation. Furthermore, while occasionally mentioned, photogrammetric data and methods are beyond the scope of this paper. Urban remote sensing science is shifting from tradition of data processing to become a foundational role in global environmental change. We focus our review on mapping, indices, and modeling, three interrelated themes (Figure 1). We begin our review by describing how remotely sensed data, with a wide variety of spatial, temporal, and spectral ranges, are used to map key environmental features of urban areas. This is followed by a discussion on representative indices of 
urban areas. The subsequent section then explores how the classified images and the indices are used to model physical and social processes. We conclude our literature review by addressing overarching gaps in the knowledge and highlight concrete steps to move forward.

Figure 1. The three themes of the literature review are interrelated and form the basic structure to describe how remote sensing data and methods support research in global environmental change.

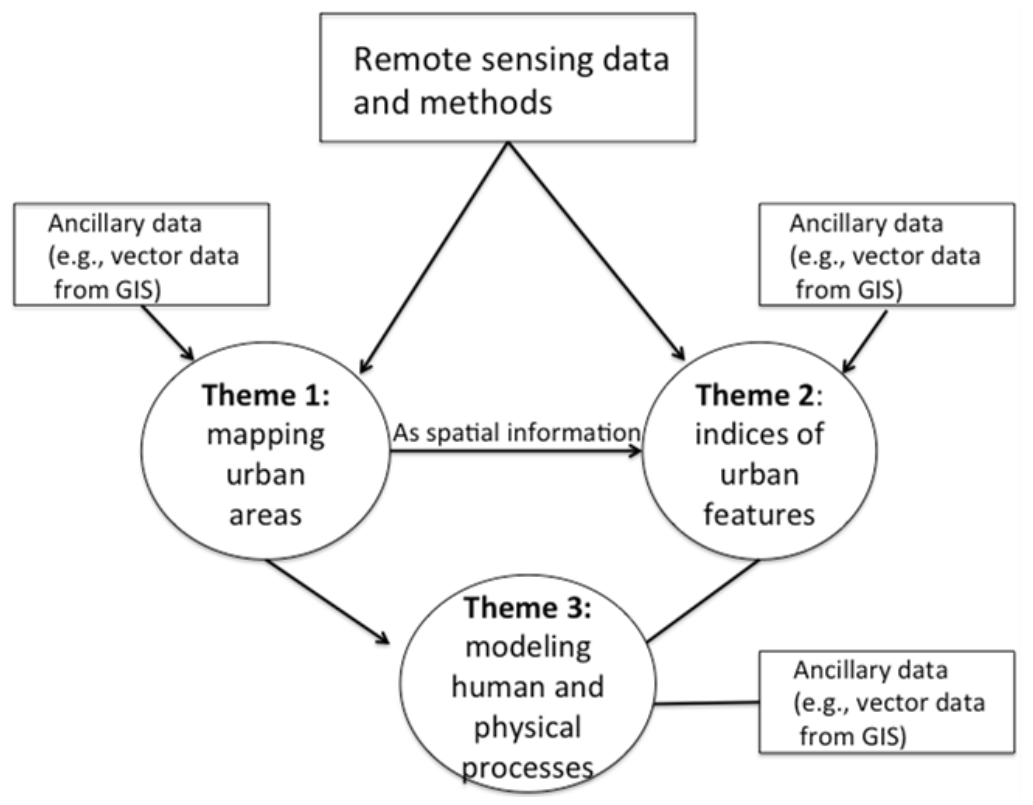

\section{Mapping Urban Areas}

The goal of this section is to describe how remotely sensed data and methods are used to create mapped information of urban areas. Mapping of urban areas can be done for a number of characteristics, including urban extent, urban land cover and land use, urban population, surface temperatures, and air quality. Each section below describes the mapped urban feature, the types of data sources and classification utilized, and research frontiers and challenges.

\subsection{Urban Extent}

The earliest urban application of remote sensing was delineation of the urban extent using aerial photography and using this information to monitor urban growth [5]. For global environmental change applications, urban extent monitoring measures where new urban areas are located, describes what type of urbanization has occurred, and leads to insights into the global impacts of this type of land transformation. Early monitoring of the urban extent in the 1970s involved tracking urban growth by identifying pixels as "urban." The main motivation for much of the early research was to document and monitor natural areas, so separating out urban from non-urban was an essential first step. Interest in delineating the urban extent, including the peri-urban, exurbia and the urban-rural fringe, fuels analysis and leads to deeper understanding of urban growth and its impacts [6,7].

The most common data sources for classifying the urban extent include optical sources such as the sensors IKONOS, Landsat, and SPOT. Using hard classifiers, whole pixels are classified as "urban" 
based on the spectral signature of impervious surface materials, as reflected from roads and buildings. More recently, data sources such as synthetic aperture radar (SAR) and nighttime lights (from the Defense Meteorological Satellite Program-Operational Linescan Program (DMSP-OLS)) are being used to identify the urban boundary [8-12]. Urban structures, including structure height, can be retrieved via SAR data to identify urban change. Likewise, nighttime lights provide input for measuring the rate of change from undeveloped to developed land when inter-calibration methods are used for consistency in multitemporal images [13]. While lights appear in rural human settlements, which are altered landscapes that are less urban; there is a higher brightness factor in urban areas (Figure 2). DMSP OLS data more accurately identify urbanization in developed countries, but are less accurate in developing countries [14].

Figure 2. Use of DMSP OLS to monitor urban growth in Atlanta Georgia and the Colorado Front Range.

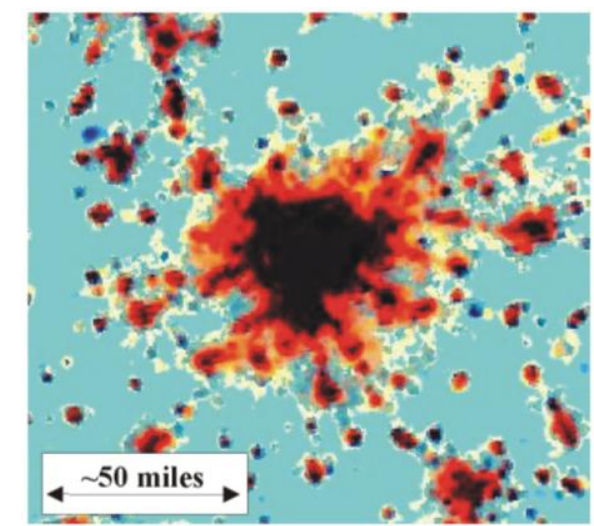

Atlanta, Georgia

Black $=$ Lights saturated in both time periods Red $=$ Lights brighter in 2000 .

Yellow $=$ Lights only present in 2000

Blue $=$ Lights only present in 1992-93

Gray $=$ Dim lighting detected in both time periods, but little change in brightness

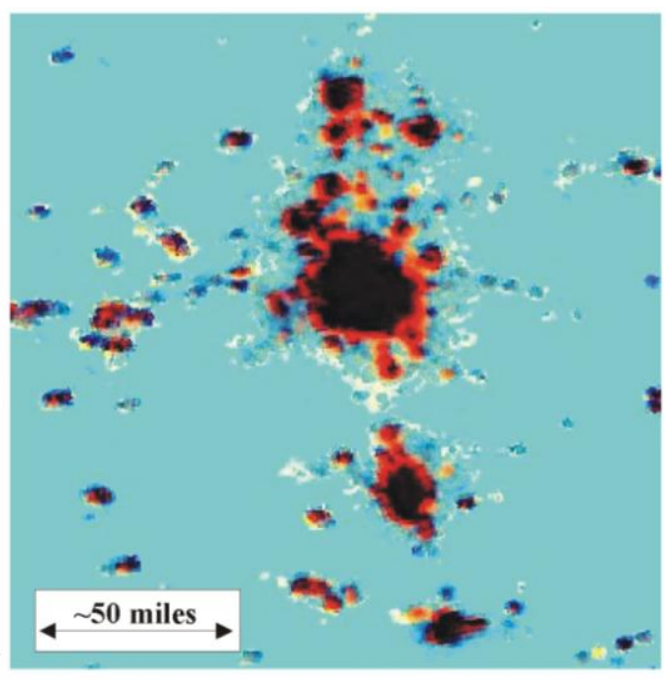

Colorado Front Range

\section{Urban expansion as observed by DMSP OLS nighttime satellite imagery (1992-3 to 2000)}

One challenge in mapping the urban extent is misclassification between urban and non-urban surfaces. In sparsely vegetated rural areas, bare rock or fallow land can have a spectral signature similar to urban impervious surfaces [15]. In contrast, some urban areas have a dense vegetation canopy, masking the underlying impervious surfaces [16]. Because of these misclassifications, documenting urban areas is particularly problematic in the transition zone from urban to rural, sometimes called the urban fringe, exurbia, or peri-urban areas [17]. One advantage of nighttime lights data is that they can be used with optical or population data to map the urban extent as a continuous rather than as a binary measure [18]. 


\subsection{Urban Composition}

Within the boundaries of the urban extent, inter-urban land surfaces are typically arranged in an elaborate tapestry of unpredictable sizes, shapes, and patterns. The goal in mapping this tapestry is to develop manual or automated methods that convert the raw spectral signals reflecting from land cover surfaces into crisp standard categories that represent the physical nature of the surface. Raw data sources typically include aerial photography and multispectral and hyperspectral optical sources, such as those described thus far. Methods for classifying urban land covers include manual classifiers [19], fuzzy and hard classifiers [20], expert systems [14,21], object-based methods [22], machine learning [23], subpixel [24], and urban spectrometry [25].

Image heterogeneity presents a major challenge in land cover classification. Pixels (of any size) in an urban area will contain a mixture of land cover surfaces with a variety of spectral signals. This mixed-pixel problem is partially resolved through a combination of fine resolution data sources (e.g., Quickbird, WorldView-1, -2) and classification methods targeting the subpixel level (e.g., subpixel analysis, spectral unmixing, Multiple-Endmember Spectral Mixture Analysis) [24]. Fine resolution data sources, however, also reflect small urban features that may or may not be part of the classification scheme (e.g., chimneys on rooftops or automobiles on road surfaces). These once invisible features may need to be filtered either during the classification or post-classification step.

Another challenge in urban land cover and mapping is translating land cover categories into land use. Because human land use is difficult to deduce directly from remotely sensed data, the interpretation of land use from land cover is predominantly inferential [26]. Nevertheless, it represents the starting point for measuring a variety of urban processes; from basic morphological changes (numbers of buildings, asphalt length, and extent of green space) to acting as a proxy for more complicated indicators such as quality of life, transport infrastructure, mixture of land use, urban ecosystems, levels of environmental sustainability, and urban structural types [27]. With reliance on context and the spatial arrangement of land cover, inference can best be described as approximate and often results in variable accuracy levels. For example, residential land use is commonly inferred from a collection of small buildings with pitched roofs, usually associated with equally small, vegetated spaces and adjacent to narrow, linear asphalt surfaces. This can result in variable patterns of density and regularity depending on prevailing planning factors of cities across the world. In contrast, commercial and industrial land uses are both inferred from land cover that represent larger, frequently flat-topped buildings, less vegetation, more adjacent imperviousness and wider asphalt surfaces. In response, classification schemes have been designed to produce a more organized and consistent list of definitions, but without using consistent and verifiable metrics [28].

The categories of land cover and land use remain highly dependent on location, data sources, and scale and in any case they pay scant attention to the more conceptual questions related to urban feature identification and links to urban growth. Indeed, these represent more recent developments in research on urban remote sensing, and include work on refining object-based algorithms to measure more complete urban land use features, linking imagery with elevation (e.g., LiDAR) to produce three-dimensional views of the city [29], as well as developing multi-paced dynamic models that add a space-time component for monitoring changes in urban land use [30-32]. Moreover, these are underscored by the search for an appropriate scale of measurement that is compatible with both sensor resolutions and 
level of urban investigation. There are essentially two groups of solutions: one is technical and involves development in sensor mechanics to allow the reproduction of spatial resolution data to match the clarity of aerial photography, and the other is institutional by prioritizing the utility of satellite sensor data for various levels of urban planning needs. The latter would involve equating spatial resolution, coverage frequency, and cost to fit within the range of planning limitations. Detailed and practical street-level planning may still be beyond the capabilities of existing satellite sensor data [33], but at the block and neighborhood scales there are many planning policies that can be based on satellite sensor data, such as measuring building density, greenness-to-imperviousness balances, roof insulation, zoning, and sprawl [34,35].

\subsection{Population}

Maps of urban population maps are used to assess health risks [35], to quantify environmental impacts of urbanization [36,37], and to assess urban infrastructures [38,39]. Early work using remote sensing inferred population by counting housing structures in aerial photography or quantifying mixtures or shifts of classified urban land cover [40]. Later, classified satellite sensor data were linked with survey-based population censuses, using, amongst many others, stochastic models [41], and inferential relationships [42-44].

Whichever means are used, population mapping from remote sensing remains approximate at best. Improvements can be achieved, at least ones that represent the basic underlying urban geography if dasymetric techniques are applied to reduce uniformity across census tracts [45]. Further improvements are also possible if intercensal forecasts can establish relationships between total classified residential land use and census totals from a base year. However, population censuses are typical of nations in the developed world; where remote sensing would be even more useful is for cities in the developing world especially for undocumented urban settlements $[46,47]$. For example, high resolution imagery (WorldView-1, WorldView-2, and Quickbird) was used to estimate populations by occupancy estimates per structure based on structure size and type (e.g., tent, hut, small building) in undocumented urban settlements and displaced populations [48].

\subsection{Surface Temperature Mapping}

Numerous studies document the strong relationship between urban land cover classes and elevated land surface temperatures in many different climate settings (see as examples, [49-53]). A unique feature of thermal infrared bands in remotely sensed data is the capability to measure land surface temperatures, and in turn, how these temperatures impact the development of an urban heat island (UHI). The use of satellite-borne infrared data for estimating surface physical properties and other related variables such as heat flux, heat storage, and reflectance, has been widely investigated as recent studies demonstrate (see [54-56]).

Studies on the UHI using satellite derived land surface temperature (LST) measurements have been conducted primarily using NOAA AVHRR data to map regional-scale urban temperatures $[57,58]$. Landsat Thematic Mapper (TM), Enhanced Thematic Mapper Plus (ETM+) thermal infrared (TIR) data, Terra Moderate Resolution Imaging Spectroradiometer (MODIS), and Advanced Spaceborne Thermal Emission and Reflection Radiometer (ASTER) have all been utilized for local-scale studies of 
the UHI $[37,59,60]$. All satellite-based studies of the UHI have either assumed or demonstrated a close relationship between the satellite-derived surface temperature and air temperature over land cover surfaces although the precise relationship become complex.

One key challenge with thermal data is that the spatial resolution of these data has not kept pace with the detailed resolution of land cover mapping data sources, which are used to quantify the drivers of temperature variations. Data sources such as Quickbird and WorldView-1, -2 with meter and submeter spatial resolutions along with object-oriented classification methods are commonly used to create high resolution land cover maps. Studies such as [60] demonstrate that surface temperatures vary depending on the spatial clustering or fractions of land cover types. These observations suggest a need for higher resolution thermal mapping to better understand the complex relationship between the drivers and variations of the thermal surface. Airborne thermal mapping, with $\sim 4 \mathrm{~m}$ and finer spatial resolution, offers the potential for high resolution access to thermal imaging for urban areas but these sources are less available than sensors on satellites [61]. This is illustrated in Figure 3 [62] where high spatial resolution $(10 \mathrm{~m})$ thermal infrared data are used to quantify daytime and nighttime surface temperatures in the Atlanta, GA central business district. Individual building rooftops can be discerned from these data which is not possible from coarser resolution thermal infrared satellite data (e.g., Landsat, ASTER, MODIS).

Figure 3. Daytime and nighttime airborne thermal infrared data collected at $10 \mathrm{~m}$ spatial resolution for the Atlanta, GA central business district. The high spatial resolution of these data permits the quantification of thermal responses from individual surfaces, including rooftops [62].
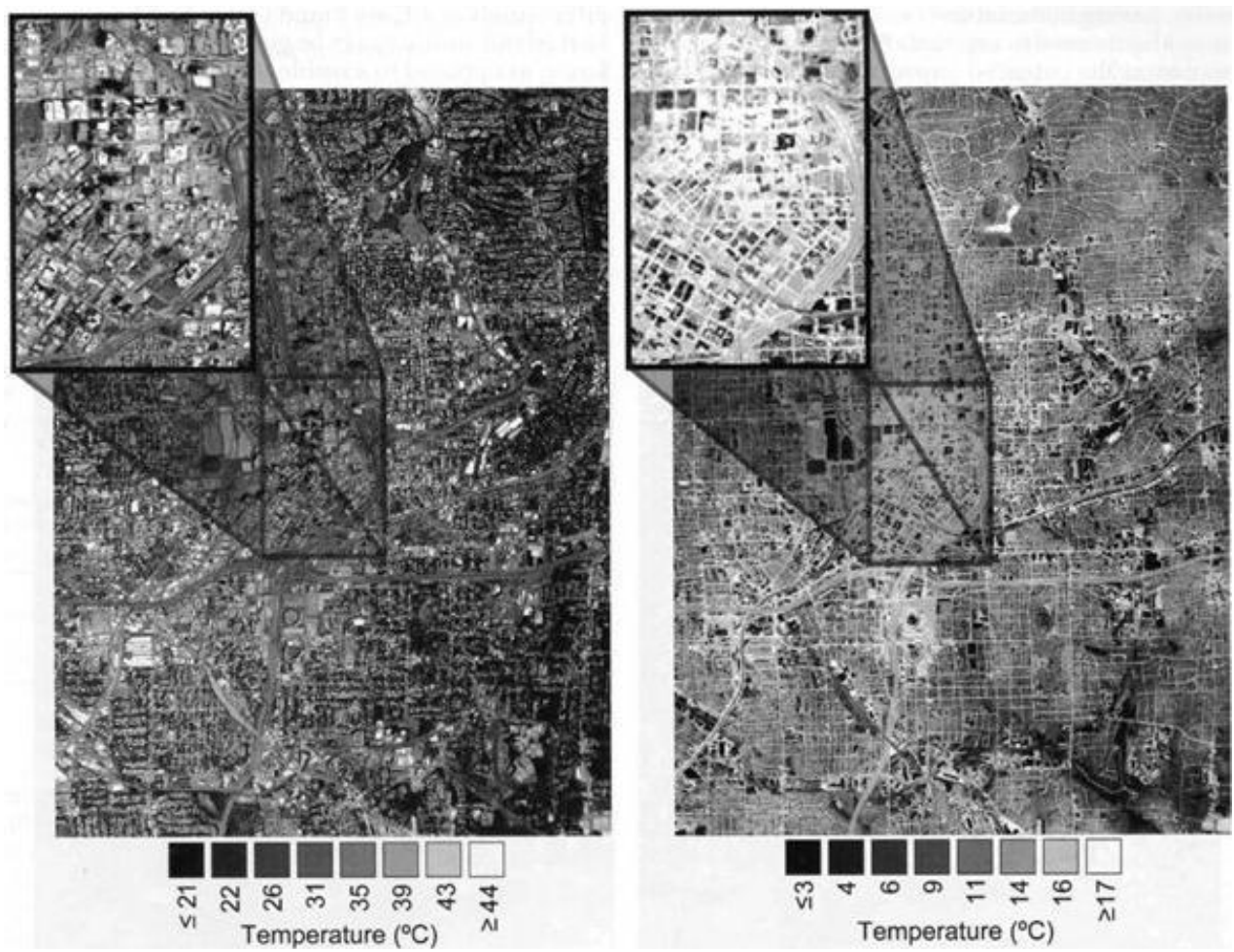


\subsection{Air Quality}

While tangible physical features at ground surface are the dominant targets for measurement by sensors that address urban environmental issues, aboveground phenomena, such as atmospheric moisture and air pollution, are also critical for generating complete views of the environmental changes made by urbanization. Pollutants and particulate matter, especially carbon monoxide (CO), nitrogen dioxide $\left(\mathrm{NO}_{2}\right)$ and sulphur dioxide $\left(\mathrm{SO}_{2}\right)$ degrade urban air quality affecting human health range from minor breathing problems, to asthma, heart diseases and lung cancer. The role of remotely sensed data is to help monitor the levels of air pollution, systematically, consistently, and frequently [63].

The most widely recognized sources for acquiring information on air pollution are two sensors onboard NASA's Terra satellite. One is the Measurements of Pollution in the Troposphere (MOPITT) sensor, which began daily data collection of $\mathrm{CO}$ concentrations profiles at a $\sim 22 \mathrm{~km}$ spatial resolution in March 2000 along with other atmospheric measurements such as surface temperature and atmospheric moisture [64]. The other sensor onboard Terra is the MODerate resolution Imaging Spectro-radiometer (MODIS) at a spatial resolution between $250 \mathrm{~m}$ and $1000 \mathrm{~m}$ globally on a one to two day cycle. MODIS is used for mapping atmospheric information such as measurements of ozone and aerosols. While the MOPITT and MODIS data are both operational for monitoring atmospheric patterns at the global and regional scales, their coarse spatial resolutions limit their practical use for mapping detailed variations over urban areas [65].

Despite challenges with the coarse resolution, several studies using MOPITT data in urban areas have helped to measure variations in CO linked to levels of urban automobile travel [66,67]. MOPITT measurements of $\mathrm{CO}$ combined with the WRF-Chem climate model, before and during the Beijing Olympics suggest that reductions in urban emissions could be met from urban traffic controls [68]. Indirect air quality modeling efforts also rely on remotely sensed data sources, in conjunction with NDVI and land use data as inputs to a regression model that maps atmospheric gases including nitric oxide, nitrogen dioxide, and nitrogen oxides, and carbon dioxide in urban areas [69,70].

\section{Urban Indices}

The data sources and mapped information described in the previous section can be re-organized or integrated with other sources to create indices that offer comparative metrics of the urban environment. In this section, we discuss common biophysical and socio-economic urban indices. We describe how they have been used to better understand the global environmental impact of cities, by describing the data and methods to calculate the indices, and limitations or possible future directions.

\subsection{Biophysical Indices}

Biophysical indices are numerical values of the biological or physical environment used to facilitate relative comparisons over space and/or time. The primary biophysical indices in urban settings using remotely sensed data aim to quantify vegetation, built-up, and water. These indices are primarily derived from passive sensors through a mathematical combination of different bands. In addition, we also describe the development and use of indices that use active sensors and ancillary data sources to calculate an index. 
Vegetation or green indices are widely used to understand the impact that urbanization has on the local and global environment. Vegetation indices quantify the relative amount of photosynthetically active vegetation on the Earth's surface, often from a ratio of the near infrared and visible bands of the electromagnetic spectrum derived from data sources such as MODIS and Landsat. Urban heat island and air quality research often rely on these vegetation indices [58,71] to calculate the cooling effect of vegetation, to quantify the role vegetation plays in improving air quality [72], and links to socioeconomic patterns [73]. Researchers have also explored how urbanization has altered net primary productivity (NPP) [74] showing losses in temperate regions and decreases in arid regions [75]. Vegetation indices are also used to model changes in surficial biogeochemistry such as nitrogen across an urban gradient showing differences between high density urban, suburban, and rural areas [48].

Vegetation indices are often used in combination with a water index, such as the normalized difference water index (NDWI) to characterize urban environmental features. The NDWI characterizes the liquid water within vegetation by incorporating two different near infrared channels measured as a ratio, much like NDVI. The NDWI in urban areas has been used to further characterize the urban heat island [76], to describe the intensity of vegetation water use [77], and to assist in water boundary delineation [78].

The biophysical index that characterizes urbanization is the built-up indices, which quantify varying factors of the biophysical environment such as impervious surfaces, building density, and urban infrastructure [79-84]. Built-up indices aim to simplify the mapping process from a land cover classification approach to a comparative metric [79], to rapidly access urban growth [80], and to characterize urban typologies [81]. The common built up indices include the normalized difference built-up index (NDBI), which is a binary index based on subtracting a vegetation index from a ratio of TM bands 4 and 5. Research to improve NDBI involves converting it from a binary to a continuous index [79]. Similarly, the normalized difference impervious surface index (NDISI) quantifies the percentage of impervious surface in a pixel [82]. Other adaptations of NDBI such as the index-based built-up index (IBI), the biophysical composition index (BCI), and the normalized difference impervious surface index (NDISI), use a combination of a vegetation index, water index, bare soil index, and the NDBI to provide coverage for a range of land cover types [78,80,84]. For example, findings show that manual methods of land cover classification compared favorably with NDBI but automated methods such as maximum likelihood performed poorly [80]. This suggests that built-up indices perform well when quantifying change in multitemporal images. Figure 4 shows example indices of NDVI, NDBI, and NDWI generated from Landsat TM image over Las Vegas.

Recently, a new spectral index, the Vegetation Adjusted Nighttime Lights (NTL) Urban Index (VANUI), combines MODIS NDVI with DMSP/OLS NTL and reduces the effects of the NTL saturation in urban areas [85]. VANUI maximizes the variability of the NTL signal within urban areas, and corresponds to specific biophysical or urban characteristics, and can be useful for studies of urban structure, energy use, and carbon emissions. Further studies are needed to correlate VANUI and other built-up indices with environmental changes across a spectrum of urban settings. 
Figure 4. Example indices generated from Landsat TM over Las Vegas: (a) NDVI; (b) NDBI; (c) NDWI.
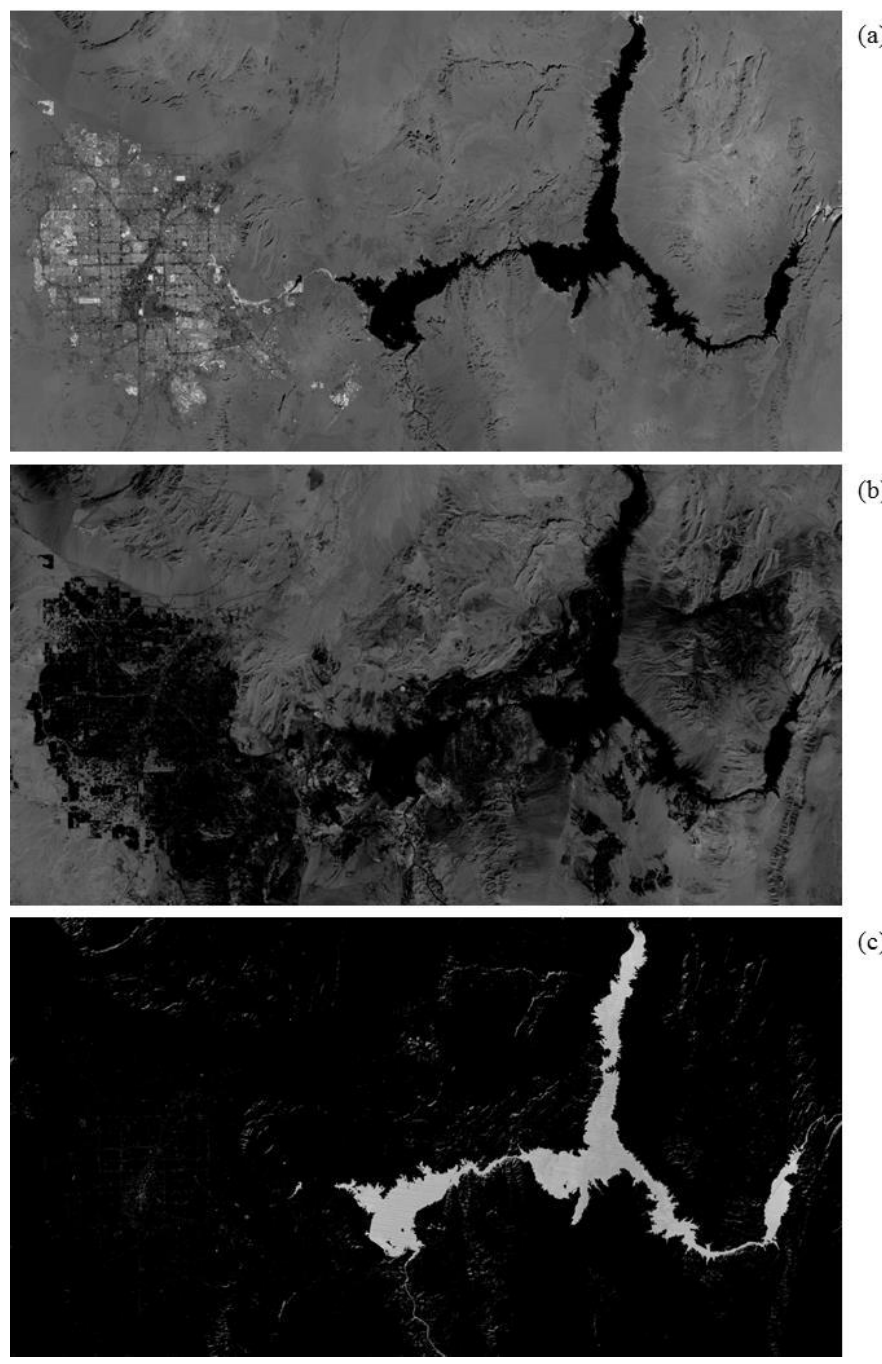

(c)

\subsection{Social and Economic Indices}

Many socio-economic indices aim to quantify the combined effects of social and economic factors that influence an individual's or a household's well-being. Typically, data on race, marital status, and education are acquired through population censuses, surveys, and ethnographic studies performed nationally or locally rather than from remotely sensed data sources. Recently researchers have explored how to capitalize on remotely sensed data to augment census and survey data. Additionally, remote sensing has been used to characterize living conditions of poor urban neighborhoods such as slums, informal settlements, marginal areas and low income neighborhoods through a combination of fine and coarse resolution data and often ancillary data [86-88]. Poverty and sub-standard housing in complex, cluttered, uncontrolled, and fast growing urbanized regions can be measured with very high spatial resolution remotely sensed data and associated geospatial techniques [89], however many challenges remain. The building materials in slums are very heterogeneous and thus are difficult to classify. Even more challenging, slums are characterized by both their physical environment (e.g., housing type) as well as socioeconomic characteristics (e.g., lack of indoor plumbing). Remote sensing studies of slums assume a strong correlation between these two elements, but this is not always 
true. Research estimated poverty using spatial indicators, such as roof densities, irregular road structures, and vegetation/impervious surface indices to characterize the physical environment (e.g., V-I-S) [88,90]. Based on these indicators, most researchers have identified, delineated, and rated neighborhoods, often to find correlations between economic variables and "positive" (e.g., vegetation) or "negative" (e.g., asphalt) environmental conditions [89,90]. In terms of the urban vegetation pattern (often analyzed with the NDVI) existing vegetation and other open areas are considered as positive urban structure elements regarding their ecological (biodiversity, production of oxygen) as well as their social function for individual recreational purposes and as socializing meeting-points. Water as a potential source of disease and the road system as air polluters are both considered as negative urban structures in the sense that their proximity can cause respiratory and infection diseases.

Light intensity data sources such as the $1 \mathrm{~km}^{2}$ resolution of the DMSP OLS also correlates strongly with economic wellness, such as national and sub-national measures of economic activity (e.g., GDP). In combination with land cover data, [91] created an index combining ecosystem services product (ESP) derived from land-cover with gross domestic product (GDP) derived from nighttime lights to identify global patterns of environmental and economic diversity. At sub-national scales economic nighttime data lead to rougher estimates of GDP, but offer clues to the magnitude of the informal economy (e.g., North Korea, Mexico, and India) [92,93]. A time series analysis of annual DMSP OLS composite data products was used to estimate changes in economic growth (change in GDP from year to year) [94]. Research shows that using the $1 \mathrm{~km}^{2}$ DMSP OLS nighttime lights as a GDP indicator varies from region to region because of different urban development patterns [95,96].

These studies exemplify the possibilities of remote sensing for identifying poverty, economic activity, and environmental risk. However, they also show that for effective poverty mapping, data aggregation may hide the spatial variations within the urban structure. So while there is success with identifying poverty, the microstructure and irregularity of fast growing urban agglomerations as well as direct adaptation of structures to local conditions and terrain, a generically applicable and operational mapping of poverty-stricken settlements has proven difficult.

\section{Modeling}

Classified images as geographic maps and derived indices from imagery are used as inputs to models for improving our understanding of urbanization processes and the interrelated impacts of urbanization on physical processes and human activities. This section describes the typical and novel applications of remotely sensed data and methods used in such studies. In particular, we focus this section on climate models, hydrologic models, urban growth models, and socio-economic models. In the end, we highlight how there are unexplored opportunities in better leveraging the methods in remote sensing to analyze physical and social phenomenon.

\subsection{Urban Climate}

Because the urban surface regulates much of the urban climate, there is a tight coupling between land use and regional climate modeling. The urban heat island is well established and documented as affected by the shape, size, and geometry of buildings. There is also mounting evidence that urbanization effects the cycling of water, carbon, aerosols and nitrogen in the climate system [97]. 
Urban climate modeling refers to micro and small-area estimates of temperature, wind speed and direction, atmospheric pressure, humidity, precipitation, energy fluxes, and atmospheric particulates in an urban area. Consistent among urban climate research is studying how urban surface features, such as the form, structure, and composition of buildings, trees, and asphalt, effect and alter these climate variables $[98,99]$. Land cover classification derived from remotely sensed data, as described earlier, are often used as inputs to urban weather and climate models such as the Fifth-Generation Penn State/NCAR Mesoscale Model (MM5), Land Use Modelling Platform (LUMPS), ENVI-met, and the Metropolitan Meteorological Experiment (METROMEX). This section describes how remote sensing methods influence temperature and precipitation modeling efforts; two of the more common topics that depend on remotely sensed data and methods [100].

Many studies show the underlying land cover influences urban atmospheric and surface temperatures. For example, studies simulated surface boundary conditions using data from remote sensing derived land cover finding air temperatures predictions were close to observational values [101,102]. Using Landsat TM in an energy balance ratio model, researchers quantify the cooling effect of wetland areas in urban areas [103]. While some studies, like the ones just described, focus on modeling surface boundary conditions, much of the urban-climate remote sensing literature addresses the urban heat island [104-106]. The UHI is elevated temperature over urban areas due to thermal energy characteristics of urban surface materials that absorb incoming shortwave solar radiation and re-emit this energy as longwave radiation from surfaces common to the city landscape (e.g., pavement, rooftops). Studies modeling UHI have been used to quantify the drivers of the UHI, to determine approaches to mitigate heat, and to analyze human, plant, and animal health, changes to rainfall patterns, and energy and water use [107-110].

Challenges that remain are acquiring data with requisite cell sizes to match thermal elements and fluxes and data collected at the time scales to monitoring diurnal temperature variations [111-114]. [115] illustrates the day/night thermal differences related to characteristics of urban morphology, such as building size, orientation, and spacing and the availability of green space, showing that the relative spatial location of land covers influences temperature more so than actual surface composition. These findings are particularly interesting because they contradict the general perception that built-up areas are warmer during the daytime as well as at night because of their surface composition (see for example [102,116-118]).

Complementary to urban temperature, remotely sensed data are also being used in urban precipitation models. Two factors in the literature are: how convective forces that drive precipitation are altered due to urbanization and how aerosols, which are highly variable in urban areas, influence rain patterns. [119] describes how multispectral satellite sensor images can be used to observe cloud particles as predictors of precipitation. For urban specific studies, have reported regional increases and locational shifts in convective precipitation due to increases to surface temperatures [100,101,119,120]. Using the precipitation radar on the Tropical Rainfall Measuring Mission (TRMM), [120] shows that the regional position of the city influences the relative increase to rainfall. The influence of aerosols on precipitation in urban areas is less clear [121]. Depending on multiple factors such as climate zone, cloud type, time of year, type and amount of atmospheric particulates, aerosols are shown to either increase or decrease precipitation. This complexity is observed using both remotely sensed data sources as well as in situ measurements of atmospheric particulates. For much of the studies modeling 
the effects of aerosols on precipitation, remotely sensed data sources such as the MOPITT derived CO data are used. Using MOPITT over the city of Ahmedabad India, [122] explored the effect of temperature and specific humidity in an atmospheric vertical column (called the mixed layer height (MHL)) and found that $\mathrm{CO}$ varied considerably in this column during the pre- and monsoon season.

\subsection{Urban Hydrology}

The structure and composition of urban areas has affected natural hydrology, such as changes to river channels, groundwater recharge, runoff, water biodiversity (flora and fauna), occurrence of floods, and water quality [123]. This is due to a large extent to urban impervious surfaces such as asphalt, concrete and buildings replacing pervious material found in rural and undeveloped places. Impervious surfaces increase the speed of runoff, change the path of the water flow, reduce groundwater recharge, and modify the patterns caused by erosion and deposition [124]. To model these processes and their consequences, hydrologic models require accurate identification and mapping of land cover, primarily impervious surfaces [123]. Remotely sensed data and methods have improved hydrologic modeling over in situ measurements, especially for gauging water quality and runoff volume $[109,125,126]$ and to a lesser extent, estimating urban water uses [127], quantifying water-born disease spread [128], and quantifying the impact on water body structures [129].

Research on water quality is focused typically at the watershed scale, examining how to protect watershed regions that drain into drinking water sources [106,130-132]. Features such as industry, roads, unplanned/illegal settlements (which tend to have poor wastewater treatment), are mapped and quantified [131,133,134]. These urban land cover maps are used as inputs to model non-point source (NPS) nutrient loadings into local water sources [135]. Research results have led to recommendations on general watershed planning, such as which areas should receive high protection status and where to located water treatment plants [131]. Some research using remotely sensed images have been used to directly assess water quality by mapping trends in water turbidity $[131,136]$.

An obvious linkage between urbanization and water quality is the amount of runoff and the nutrient content, typically estimated by impervious surfaces [123]. Most models of urbanization affects on runoff show that urbanization increases runoff amounts and rates because of reduced percolation into the ground [137-139]. Remotely sensed data including SPOT, Quickbird, and Landsat have been used to quantify runoff under normal and storm precipitation events [140,141]. Research has shown that land use type alone is not an effective proxy for impervious surface quantity and that that finer resolution data are more appropriate for mapping impervious surfaces for runoff models [142,143]. [139] found the best accuracy in mapping impervious surfaces occurred when statistical tools (e.g., Impervious Surface Analysis Tool) combined remotely sensed data sources with population (e.g., US census data). Runoff models using impervious surface mapping have led to improved understanding of groundwater quality and recharge [144-146], floodplain management, and coastal flooding [147-149].

Researchers have also used remotely sensed images to estimate urban water demand, including for drinking supply, urban agriculture, and landscaping. Researchers used remotely sensed data to map the boundaries of residential area and density to facilitate planning and construction of water infrastructure $[127,150]$. Landsat data were used to calculate the NDVI along with climate information 
and seasons to estimate water consumption for urban agriculture [151]. Similarly, [152] estimated landscape irrigation needs in Salt Lake City Utah from landscape type derived from multispectral imagery and measurements of evapotranspiration.

\subsection{Urban Land Change and Expansion}

The expansion of urban areas into other land covers drives environmental change, including climate, hydrological systems, biogeochemistry, and habitat loss. Moreover, the ways in which urban areas expand, including their form and structure affects travel demand, infrastructure needs, and energy consumption. As a simplification of reality, urban growth models represent both the form and structure of urbanization, and their success lie in retaining fundamental urban characteristics by simplifying reality as much as necessary, and at least to its level of "usefulness", although utility is not always succinctly stated or demonstrated.

There are dozens of land use models available (see [153,154]). This proliferation reflects in part the wide availability of input data, such as remote sensing, and methodological progress in the attempt to understand or predict the nature of the landscape, the types of changes occurring, the causal structure connecting the underlying factors of change, and the hypotheses tested. The difference between them varies from data sources, methodological differences, model objectives, geographic context, political environments, and cultural settings.

Classified data from remote sensing systems are the principal inputs to many of the urban growth models $[155,156]$. The availability of global coverage satellite data is changing the nature of urban land change modeling from a focus on individual cities or regions to the potential to model urban land change globally. While most models utilize land cover classification schemes, some modeling efforts also incorporate population estimates and biophysical indices. Remotely sensed data sources and the derivative data sets of information will continue to be widely needed for growth models given that the majority of the future urban population growth is expected to occur in the developing world, which often lack local mapping and modeling efforts [95].

One challenge faced is that land use change modeling is currently weakly coupled with land use planning. Urban land change models often claim policy-relevance usefulness but lack spatial detail or specific information that is either policy-relevant or useful. Tighter coupling can be achieved by explicitly introducing a policymaking module in a land use change model - although this may not be practical in developing countries given political realities and adverse access to resources. These also require the concomitant socioeconomic data to develop detailed models of urban expansion.

\subsection{Social and Economic Modeling}

Modeling the social and economic conditions of urban areas is beginning to utilize data provided by remote sensing methods to understand, characterize, and simulate human quality of life. The models that include remote sensing focus on human health and economic conditions. Model outcomes can be used to create planning tools, evaluate policy options, and assess urban inequities. While many models do use remote sensing data and methods, those that include quality of life dimensions such as family and community life, education, political freedom, and gender equality typically do not use remotely sensed data sources. This section focuses on the former. 
Human health modeling efforts strive to quantify conditions that promote or harm human health such as linkages between urban structure and obesity, vector borne or infectious disease transmission and spread, and the impact of extreme heat and air quality on health [157]. One area that has effectively used remotely sensed data is classification of urban water bodies leading to insights into the spread of disease. Water body mapping can identify breeding locations of disease vectors such as mosquitoes [128]. [158] shows that larger water areas, including stream length and wetland size, result in higher risks in disease outbreaks. SPOT high resolution data were used to analyze and model the spatial variations of land surface temperatures in Paris during summer heat waves and correlated extreme temperatures to deaths in the elderly population [118]. The public health community has begun to use remote sensing data in combination with ground surveys and census data to identify populations at risk.

However, there are many studies that quantify health outcomes and urban environment data compiled from sources other than remote sensing. For example, in several of the seminal works on obesity and the built environment, tax assessor's records rather than data from satellite or other forms of remote sensing are used to characterize the urban form [159]. On the other hand, studies that quantify urban environmental characteristics such as air quality simply make inferences to the impact on human health rather than making an explicit quantification (e.g., air pollution monitoring and asthma).

A second quality of life factor modeled using remote sensing methods is economic development [89]. Much of this research uses land cover or use maps derived from remotely sensed images and correlate these with economic growth and stability. Geographers were the first to utilize DMSP OLS to examine economic activity [93]. While most existing studies have emphasized associations at high levels of data aggregation such as countries, increasingly applications at the subnational level emerge with efforts led by economists [160,161].

\section{Gaps in Knowledge and Future Opportunities}

Understanding the global impact of urbanization requires large amounts of information based on the multi-dimensional aspects of urbanization. Remotely sensed data and methods are well positioned to contribute to this effort. As this review illustrates, there is considerable growth in using remotely sensed data to support the understanding cities through mapping, indices, and modeling of human activities and environmental processes. A common theme among the articles we highlighted is that researchers are utilizing a variety of data sources coupled with novel classification methods and integrating these results into modeling efforts.

Scale remains a crosscutting theme in urban remote sensing that includes on the surface spatial resolution, temporal repeat frequency, and spectral resolution. Scale along all dimensions represents a level of detail and, to some extent, a level of accuracy. Spatial resolution, temporal frequency, and spectral detail are often inversely related. For monitoring urban areas, low spatial resolution data, such as the MOPITT data, presents a challenge for acquiring the spatial distribution and pattern across an urban area. In isolation, scale is problematic but the challenge is compounded when data are coupled with other sources. As ancillary data (e.g., vector data from geographic information systems) are used in expert systems to improve classification accuracy, the spatial and temporal correspondence between data sources becomes critical. Linkages between social, biological, and physical characteristics are 
challenging to integrate because of poor correspondence between temporal scales (data collection intervals) and spatial scales (administrative units and landscape units).

To address scale issues, there are plans for obtaining finer spatial and spectral resolution data to improve remote sensing observation and analysis of urban areas. For example, the Hyperspectral Infrared Imager (HyspIRI) which is planned for launch later this decade, will have a hyperspectral Visible and ShortWave Infrared (VSWIR) spectrometer with bandwidths of 380 to $2500 \mathrm{~nm}$ in $10 \mathrm{~nm}$ band increments [162]. It will also have a multispectral thermal infrared instrument with 8 bands in the 3.9-12.3 $\mu \mathrm{m}$ spectral bandwidth. HyspIRI will have a spatial resolution of $60 \mathrm{~m}$ and a repeat cycle of 16 days, with the capability of acquiring both daytime and nighttime measurements. The VSWIR and thermal infrared data obtained by HyspIRI can be used to provide integrated higher level datasets for use in developing detailed quantitative information on spectral responses and surface temperatures for the surface material types that comprise the heterogeneous urban landscape (Figure 5).

Figure 5. HyspIRI hyperspectral Visible and ShortWave Infrared (VSWIR) and thermal infrared data will provide the capability for deriving higher level integrated data products for quantitative measurement of surface reflectances and temperatures for the land surface components and material types that comprise the complex urban landscape.

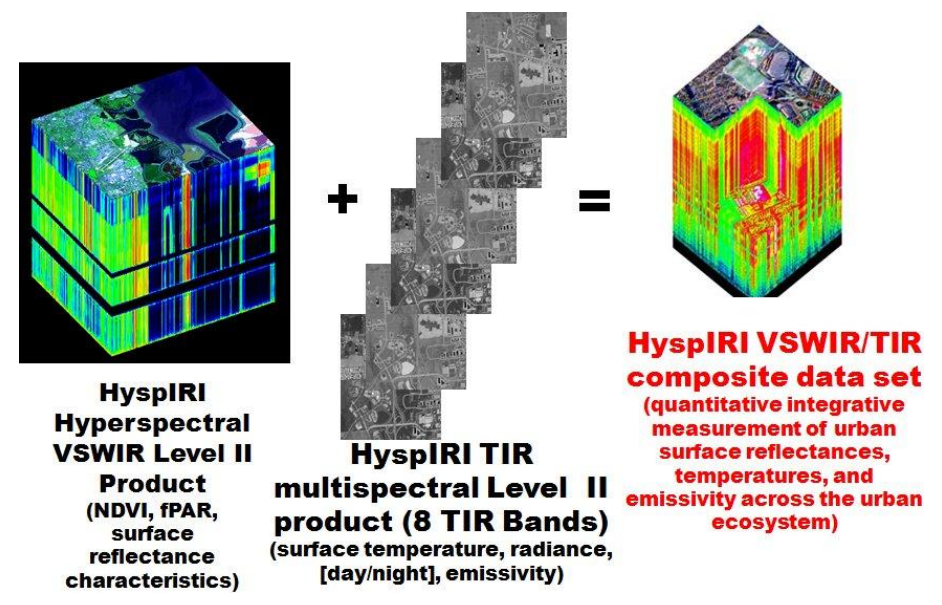

Cloud-computing based platforms such as Google's Earth Engine, the NASA Earth Exchange (NEX), and NSF's Earth Cube are transforming how we access and process data at all spatial, temporal, and spectral scales. Access to these data sources will fundamentally change the types of research questions we can ask. These data and information dissemination methods facilitate greater access to knowledge of urbanization processes with the ability to move away from single scene analysis to multitemporal and whole-world analyses. These data sources develop into "Big Data" issues that simultaneously become opportunities and challenges in solving scientific, analytical, and political issues. The opportunities are the ability to perform spatial decomposition, to examine the diversity of patterns, and to better understand outliers. Critical to the use of big data is first identifying the research question or theory to be tested. Otherwise, a key challenge with "Big Data" involves "finding a needle in a haystack", dealing with the noise to extract the real information, and addressing anonymity and privacy concerns.

Remote sensing scientists do not limit themselves to data sources collected through satellite sensors, to conventional classification methods, or to specific applications. Instead, new data sources, methods, 
and applications areas are continually being explored. Unexplored or underutilized data sources that could be integrated with satellite sensor data include social media, cell phone tracking, and volunteered geographic information [163]. These can be combined with advanced analytical approaches including data mining, machine learning, agent-based models, and Bayesian methods. The coupling of remotely sensed data and alterative data sources and sophisticated modeling leads to the possibility of mapping and analyzing new application topics. Emerging and urgent challenges that influence global environmental change studies include mapping food deserts, mapping disease spread in cities, real-time transportation information, and many others.

While data and knowledge improve our understanding of cities, this reflects just one dimension of urbanization science. We also need to build collaborations between science and policy, including the data providers, climate scientists, planners, and policy- and decision-makers. In the modern era of science, we recognize that we must observe and understand urbanization as a process and strive to use theories and knowledge to direct and enable a sustainable future.

\section{Acknowledgments}

This material is based upon work supported by NASA Grant No. NNX10AN11G and the National Science Foundation Grant No. GSS-023907. Any opinions, findings and conclusions, or recommendation expressed here are those of the authors and do not necessarily reflect the views of the funding agencies. The authors also acknowledge contributions from the Forecasting Urban Land-use Change Workshop (NASA) and the Urban Remote Sensing Workshop (NSF) participants: Rimjhim Aggarwal, Shlomo (Solly) Angel, Philip Christensen, Keith Clarke, Richard Dawson, Fabio Dell'Aqua, Xiangzheng Deng, Peter Omu Elias, Jonathan Fink, Tyler Frazier, Arjit Guha, Subhro Guhathakurta, Burak Güneralp, Geoffrey Henebry, Clair Jantz, Shai Kaplan, Donghwan Kim, José Lobo, Miguel Luengo-Oroz, Jacqueline Lu, Darle Monroe, David Nelson, Robert (Gil) Pontius, Milap Punia, Lela Preshad, Ray Quay, Charles Redman, Qing Shen, Christopher Small, William Solecki, Tod Swanson, Scott Weisman, and Sainan Zhang. We also acknowledge Cary Simmons and Qian Zhang for help with graphics.

\section{Author Contributions}

Elizabeth A. Wentz led the effort and wrote the majority of the manuscript; Sharolyn Anderson created a figure and wrote one section; Michail Fragkias wrote one section and provided editorial comments; Maik Netzband contributed to one section and provided editorial comments; Victor Mesev contributed to one section and provided editorial comments; Soe W. Myint created a figure and contributed to one section; Dale Quattrochi contributed to one section and created a figure; Atiqur Rahman provided editorial feedback; and Karen C. Seto contributed to one section and provided editorial feedback.

\section{Conflicts of Interest}

The authors declare no conflict of interest. 


\section{References}

1. Solecki, W.; Seto, K.C.; Marcotullio, P.J. It's time for an urbanization science. Environ.: Sci. Policy Sustain. Dev. 2013, 55, 12-17.

2. Wentz, E.A.; Quattrochi, D.; Netzband, M.; Myint, S. Synthesizing urban remote sensing through application, scale, data and case studies. Geocarto Int. 2012, 27, doi:10.1080/10106049.2012.687400.

3. Weng, Q. Global Urban Monitoring and Assessment through Earth Observation; CRC Press/Taylor and Francis: Boca Raton, FL, USA, 2014.

4. Patino, J.E.; Duque, J.C. A review of regional science applications of satellite remote sensing in urban settings. Comput. Environ. Urban Syst. 2013, 37, 1-17.

5. Bowden, L.W.; Brooner, W.G. Aerial photography: A diversified tool. Geoforum 1970, 1, 19-32.

6. Weng, Q. A remote sensing-GIS evaluation of urban expansion and its impact on surface temperature in the Zhujiang Delta, China. Int. J. Remote Sens. 2001, 22, 1999-2014.

7. Ridd, M.K. Exploring a V-I-S (Vegetation-Impervious surface-Soil) model for urban ecosystem analysis through remote-sensing-comparative anatomy for cities. Int. J. Remote Sens. 1995, 16, 2165-2185.

8. Grey, W.; Luckman, A. Mapping urban extent using satellite radar interferometry. Photogramm. Eng. Remote Sens. 2003, 69, 957-962.

9. Imhoff, M.; Lawrence, W.T.; Stutzer, D.C.; Elvidge, C.D. A technique for using composite DMSP/OLS “city lights" satellite data to map urban area. Remote Sens. Environ. 1997, 61, 361-370.

10. Elvidge, C.D.; Baugh, K.E.; Kihn, E.A.; Kroehl, R.W.; Davis, E.R. Mapping city lights with nighttime data from the DMSP operational linescan system. Photogramm. Eng. Remote Sens. 1997, 63, 727-734.

11. Elvidge, C.D.; Baugh, K.E.; Dietz, J.B.; Bland, T.; Sutton, P.C.; Kroehl, H.W. Radiance calibration of DMSP-OLS low-light imaging data of human settlements. Remote Sens. Environ. 1999, 68, 77-88.

12. Small, C.; Pozzi, F.; Elvidge, C.D. Spatial analysis of global urban extent from DMSP-OLS night lights. Remote Sens. Environ. 2005, 96, 277-291.

13. Li, X.; Chen, X.; Zhao,Y.; Xu, J.; Chen, F.; Li, H. Automatic intercalibration of night-time light imagery using robust regression. Remote Sens. Lett. 2013, 4, 45-54.

14. Zhang, Q.; Seto, K. Can night-time light data identify typologies of urbanization? A global assessment of successes and failures. Remote Sens. 2013, 5, 3476-3494.

15. Stefanov, W.L.; Ramsey, M.S.; Christensen, P.R. Monitoring urban land cover change: An expert system approach to land cover classification of semiarid to arid urban centers. Remote Sens. Environ. 2001, 77, 173-185.

16. Sung, C.Y.; Li, M.-H. Considering plant phenology for improving the accuracy of urban impervious surface mapping in a subtropical climate regions. Int. J. Remote Sens. 2012, 33, 261-275.

17. Sutton, P.C.; Cova, T.J.; Elvidge, C.D. Mapping "exurbia" in the conterminous United States using nighttime satellite imagery. Geocarto Int. 2006, 21, 39-45. 
18. Elvidge, C.D.; Milesi, C.; Dietz, J.B.; Tuttle, B.T.; Sutton, P.C.; Nemani, R.; Vogelmann, J.E. US constructed area approaches the size of Ohio. Eos Trans. Am. Geophys. Union 2004, 85, 233-233.

19. Kara, B.; Esbah, H.; Deniz, B. Monitoring and analyzing land use/land cover changes in a developing coastal town: A case study of Kusadasi, Turkey. J. Coast. Res. 2013, 29, 1361-1372.

20. Lizarazo, I.; Barros, J. Fuzzy image segmentation for urban land-cover classification. Photogramm. Eng. Remote Sens. 2010, 76, 151-162.

21. Hermosilla, T.; Ruiz, L.A.; Recio, J.A.; Cambra-López, M. Assessing contextual descriptive features for plot-based classification of urban areas. Landsc. Urban Plan. 2012, 106, 124-137.

22. Blaschke, T. Object based image analysis for remote sensing. ISPRS J. Photogramm. Remote Sens. 2010, 65, 2-16.

23. Tuia, D.; Camps-Valls, G. Urban image classification with semisupervised multiscale cluster kernels. IEEE J. Sel. Top. Appl. Earth Obs. Remote Sens. 2011, 4, 65-74.

24. Song, C.H. Spectral mixture analysis for subpixel vegetation fractions in the urban environment: How to incorporate endmember variability? Remote Sens. Environ. 2005, 95, 248-263.

25. Herold, M.; Roberts, D.A.; Gardner, M.E.; Dennison, P.E. Spectrometry for urban area remote sensing-Development and analysis of a spectral library from 350 to $2400 \mathrm{~nm}$. Remote Sens. Environ. 2004, 91, 304-319.

26. Barnsley, M.J.; Barr, S.L. A graph-based, structural pattern recognition system to infer urban land-use from fine spatial resolution land-cover data. Comput. Environ. Urban Syst. 1997, 21, 209-225.

27. Bochow, M.; Taubenböck, H.; Segl, K.; Kaufmann, H. An Automated and Adaptable Approach for Characterizing and Partitioning Cities into Urban Structure Types. In Proceedings of the 2010 IEEE International Geoscience and Remote Sensing Symposium (IGARSS), Honolulu, HI, USA, 25-30 July 2010; pp. 1796-1799

28. Anderson, J.R.; Hardy, E.E.; Roach, J.T.; Witmer, R.E. A Land Use and Land Cover Classification System for Use with Remote Sensor Data; Geological Survey Professional Paper 964; US Government Printing Office: Washington, DC, USA, 1976.

29. Aubrecht, C.; Steinnocher, K.; Hollaus, M.; Wagner, W. Integrating earth observation and GIScience for high resolution spatial and functional modeling of urban land use. Comput. Environ. Urban Syst 2009, 33, 15-25.

30. Brown, D.G.; Walker, R.; Manson, S.M.; Seto, K.C. Modeling Land Use and Land Cover Change. In Land Change Science: Observing, Monitoring, and Understanding Trajectories of Change on the Earth's Surface; Gutman, G., Janetos, A., Justice, C., Moran, E., Mustard, J., Rindfuss, R., Skole, D., Turner B.L., II, Eds.; Kluwer Academic Publishers: Dordrecht, The Netherlands, 2004; pp. 395-409.

31. Taubenböck, H.; Esch, T.; Felbier, A.; Wiesner, M.; Roth, A.; Dech, S. Monitoring urbanization in mega cities from space. Remote Sens. Environ. 2012, 117, 162-176.

32. Mesev, V. Exploring the Temporal Lag between the Structure and Function of Urban Areas. In Urban Remote Sensing: Monitoring, Synthesis and Modeling in the Urban Environment; Yang, X., Ed.; Wiley-Blackwell: West Sussex, UK, 2011; pp. 155-162. 
33. Hoalst Pullen, N.; Patterson, M.W. Applications and trends of remote sensing in professional urban planning. Geogr. Compass 2011, 5, 249-261.

34. Hasse, J.E.; Lathrop, R.G. Land resource impact indicators of urban sprawl. Appl. Geogr. 2003, 23, 159-175.

35. Aubrecht, C.; Oezceylan, D.; Steinnocher, K.; Freire, S. Multi-level geospatial modeling of human exposure patterns and vulnerability indicators. Nat. Hazards 2013, 68, 147-163.

36. Harper, S. Population-environment interactions: European migration, population composition and climate change. Environ. Resour. Econ. 2013, 55, 525-541.

37. Javed, M.; Rahman, A. Impact of population density on the surface temperature and micro-climate of Delhi. Curr. Sci. 2012, 102, 1708-1713.

38. Armenakis, C.; Nirupama, N. Estimating spatial disaster risk in urban environments geomatics. Nat. Hazards Risk 2013, 4, 289-298.

39. Brown, V.; Jacquier, G.; Coulombier, D.; Balandine, S.; Belanger, F.; Legros, D. Rapid assessment of population size by area sampling in disaster situations. Disasters 2001, 25, 164-171.

40. Lo, C.P. Automated population and dwelling unit estimation from high-resolution satellite images: A GIS approach. Remote Sens. 1995, 16, 17-34.

41. Mesev, V. The use of census data for urban image classification. Photogramm. Eng. Remote Sens. 1998, 64, 431-438.

42. Sutton, P.; Roberts, D.; Elvidge, C.; Meij, H. A comparison of nighttime satellite imagery and population density for the continental United States. Photogramm. Eng. Remote Sens. 1997, 63, 1303-1313.

43. Harvey, J.T. Population estimation models based on individual TM pixels. Photogramm. Eng. Remote Sens. 2002, 68, 1181-1192.

44. Li, G.; Weng, Q. Using Landsat ETM+ imagery to measure population density in Indianapolis, Indiana, USA. Photogramm. Eng. Remote Sens. 2005, 71, 947-958.

45. Mennis, J. Generating surface models of population using dasymetric mapping. Prof. Geogr. 2003, 55, 31-42.

46. Bjorgo, E. Using very high spatial resolution multispectral satellite sensor imagery to monitor refugee camps. Int. J. Remote Sens. 2000, 21, 611-616.

47. Lang, S.; Tiede, D.; Hölbling, D.; Füreder, P.; Zeil, P. Earth observation (EO)-based ex post assessment of internally displaced person (IDP) camp evolution and population dynamics in Zam Zam, Darfur. Int. J. Remote Sens. 2010, 31, 5709-5731.

48. Checchi, F.; Stewart, B.T.; Palmer, J.J.; Grundy, C. Validity and feasibility of a satellite imagery-based method for rapid estimation of displaced populations. Int. J. Health Geogr. 2013, $12,1-12$.

49. Chen, X.L.; Zhao, H.M.; Li, P.X.; Yin, Z.Y. Remote sensing image-based analysis of the relationship between urban heat island and land use/cover changes. Remote Sens. Environ. 2006, 104, 133-146.

50. He, J.F.; Lin, J.Y.; Zhuang, D.F.; Zhang, W.; Lin, M.L. Assessing the effect of land use/land cover change on the change of urban heat island intensity. Theor. Appl. Climatol. 2007, 90, 217-226.

51. Jensen, R.; Hardin, P.J.; Curran, R.; Hardin, T. The relationship between urban land cover and surface kinetic temperature: A case study in Terra Haute, Indiana. J. Terr. Obs. 2010, 2, 46-65. 
52. Rinner, C.; Hussain, M. Toronto's urban heat island-Exploring the relationship between land use and surface temperature. Remote Sens. 2011, 3, 1251-1265.

53. Ogashawara, I.; da Silva Brum Bastos, V. A quantitative approach for analyzing the relationship between urban heat islands and land cover. Remote Sens. 2012, 4, 3596-3618.

54. Kato, S.; Yamaguchi, Y. Estimation of storage heat flux in an urban area using ASTER data. Remote Sens. Environ. 2007, 110, 1-17.

55. Lu, D.; Weng, Q. Use of impervious surface in urban land-use classification. Remote Sens. Environ. 2006, 102, 146-160.

56. Small, C. Comparative analysis of urban reflectance and surface temperature. Remote Sens. Environ. 2006, 104, 168-189.

57. Gallo, K.P.; Owen, T.W. Assessment of urban heat Islands: A multisensor perspective for the Dallas, Ft. Worth, USA region. Geocarto Int. 1998, 13, 35-41.

58. Streutker, D.R. A remote sensing study of the urban heat island of Houston, Texas. Int. J. Remote Sens. 2002, 23, 2595-2608.

59. Yuan, F.; Bauer, M.E. Comparison of impervious surface area and normalized difference vegetation index as indicators of surface urban heat island effects in Landsat imagery. Remote Sens. Environ. 2007, 106, 375-386.

60. Myint, S.W.; Wentz, E.A.; Brazel, A.J.; Quattrochi, D.A. The impact of distinct anthropogenic and vegetation features on urban warming. Landsc. Ecol. 2013, 28, 959-978.

61. Oltra-Carrio, R.; Sobrino, J.A.; Franch, B.; Nerry, F. Land surface emissivity retrieval from airborne sensor over urban areas. Remote Sens. Environ. 2012, 123, 298-305.

62. Quattrochi, D.A.; Luvall, J.C.; Rickman, D.L.; Estes, M.G., Jr.; Laymon, C.A.; Howell, B.F. A decision support system for urban landscape management using thermal infrared data. Photogramm. Eng. Remote Sens. 2000, 66, 1195-1207.

63. Evans, J.; van Dokelaar, A.; Martin, R.V.; Burnett, R.; Rainham, D.G.; Birkett, N.J.; Drewski, D. Estimates of global mortality attributable to particulate air pollution using satellite imagery. Environ. Res. 2013, 120, 33-42.

64. Deeter, M.N. MOPITT (Measurements of Pollution in the Troposphere); Version 5 Product User's Guide; National Aeronautics and Space Administration (NASA): Washington, DC, USA, 2011.

65. Martin, R.V. Satellite remote sensing of surface air quality. Atmos. Environ. 2008, 42, 7823-7843.

66. Clerbaux, C.; Edwards, D.P.; Deeter, M.; Emmons, L.; Lamarque, J.F.; Tie, X.X.; Gille, J. Carbon monoxide pollution from cities and urban areas observed by the Terra/MOPITT mission. Geophys. Res. Lett. 2008, 35, doi:10.1029/2007GL032300.

67. Hao, N.; Valks, P.; Loyola, D.; Cheng, Y.F.; Zimmer, W. Space-based measurements of air quality during the World Expo 2010 in Shanghai. Environ. Res. Lett. 2011, 6, doi:10.1088/1748-9326/6/4/044004.

68. Worden, H.M.; Cheng, Y.; Pfister, G.; Carmichael, G.R.; Zhang, Q.; Streets, D.G.; Deeter, M.; Edwards, D.P.; Gille, J.C.; Worden, J.R. Satellite based estimates of reduced $\mathrm{CO}$ and $\mathrm{CO}_{2}$ emissions due to traffic restrictions during the 2008 Beijing Olympics. Geophys. Res. Lett. 2012, 39, doi:10.1029/2012GL052395. 
69. Su, J.G.; Jerrett, M.; Beckerman, B.; Wilhelm, M.; Ghosh, J.K.; Ritz, B. Predicting traffic-related air pollution in Los Angeles using a distance decay regression selection strategy. Environ. Res. 2009, 109, 657-670.

70. Wentz, E.A.; Gober, P.; Balling, R.C., Jr.; Day, T.A. Spatial patterns and determinants of winter atmospheric carbon dioxide concentrations in an urban environment. Ann. Assoc. Am. Geogr. 2002, 92, 15-28.

71. Qiao, Z.; Tian, G.; Xiao, L. Diurnal and seasonal impacts of urbanization on the urban thermal environment: A case study of Beijing using MODIS data. ISPRS J. Photogramm. Remote Sens. 2013, 85, 93-101.

72. Kim, S.W.; Heckel, A.; McKeen, S.A.; Rost, G.J.; Hsie, E.Y.; Trainer, M.K.; Richter, A.; Burrows, J.P.; Peckham, S.E.; Grell, G.A. Satellite observed US power plant $\mathrm{NO}_{\mathrm{x}}$ emission reductions and their impact on air quality. Geophys. Res. Lett. 2006, 33, doi:10.1029/2006GL027749.

73. Buyantuyev, A.; Wu, J. Urban heat islands and landscape heterogeneity: Linking spatiotemporal variations in surface temperatures to land-cover and socioeconomic patterns. Landsc. Ecol. 2010, $25,17-33$.

74. Gupta, K.; Kumar, P.; Pathan, S.K.; Sharma, K.P. Urban Neighborhood Green Index-A measure of green spaces in urban areas. Landsc. Urban Plan. 2012, 105, 325-335.

75. Buyantuyev, A.; Wu, J. Urbanization alters spatiotemporal patterns of ecosystem primary production: A case study of the Phoenix metropolitan region, USA. J. Arid Environ. 2009, 73, 512-520.

76. Rao, P.; Hutyra, L.R.; Raciti, S.M.; Finzi, A.C. Field and remotely sensed measures of soil and vegetation carbon and nitrogen across an urbanization gradient in the Boston metropolitan area. Urban Ecosyst. 2013, 16, 593-616.

77. Nouri, H.; Beecham, S.; Hassanli, A.M.; Kazemi, F. Water requirements of urban landscape plants: A comparison of three factor-based approaches. Ecol. Eng. 2013, 57, 276-284.

78. $\mathrm{Xu}, \mathrm{H}$. Modification of Normalized Difference Water Index (NDWI) to enhance open water features in remotely sensed imagery. Int. J. Remote Sens. 2006, 27, 3025-3033.

79. Varshney, A. Improved NDBI differencing algorithm for built-up regions change detection from remote-sensing data: An automated approach. Remote Sens. Lett. 2013, 4, 504-512.

80. Zha, Y.; Gao, J.; Ni, S. Use of normalized difference built-up index in automatically mapping urban areas from TM imagery. Int. J. Remote Sens. 2003, 24, 583-594.

81. Vanderhaegen, S.; Canters, F. Developing urban metrics to describe the morphology of urban areas at block level. Int. Arch. Photogramm. Remote Sens. Spat. Inf. Sci. 2010, 36, 192-197.

82. $\mathrm{Xu}, \mathrm{H}$. Analysis of impervious surface and its impact on urban heat environment using the Normalized Difference Impervious Surface Index (NDISI). Photogramm. Eng. Remote Sens. 2010, 76, 557-565.

83. As-Syakur, A.R.; Adnyana, I.; Arthana, I.W.; Nuarsa, I.W. Enhanced Built-Up and Bareness Index (EBBI) for mapping built-up and bare land in an urban area. Remote Sens. 2012, 4, 2957-2970. 
84. He, C.; Shi, P.; Xie, D.; Zhao, Y. Improving the normalized difference built-up index to map urban built-up areas using a semiautomatic segmentation approach. Remote Sens. Lett. 2010, $1,213-221$.

85. Zhang, Q.; Schaaf, C.; Seto, K.C. The Vegetation Adjusted NTL Urban Index: A new approach to reduce saturation and increase variation in nighttime luminosity. Remote Sens. Environ. 2013, $129,32-41$.

86. Kit, O.; Luedeke, M. Automated detection of slum area change in Hyderabad, India using multitemporal satellite imagery. ISPRS J. Photogramm. Remote Sens. 2013, 83, 130-137.

87. Taubenböck H.; Kraff, N. The physical face of slums-A structural comparison of slums in Mumbai, India based on remotely sensed data. J. Built Environ. 2013, doi:10.1007/s10901-013-9333-x.

88. Stow, D.A.; Lippitt, C.D.; Weeks, J.R. Geographic object-based delineation of neighborhoods of Accra, Ghana using QuickBird satellite imagery. Photogramm. Eng. Remote Sens. 2010, 76, 907-914.

89. Baud, I.; Kuffer, M.; Pfeffer, K.; Sliuzas, R.; Karuppannan, S. Understanding heterogeneity in metropolitan India: The added value of remote sensing data for analyzing sub-standard residential areas. Int. J. Appl. Earth Obs. Geoinf. 2010, 12, 359-374.

90. Sluizas, R.; Kuffer, M. Analysing the Spatial Heterogeneity of Poverty Using Remote Sensing: Typology of Poverty Areas Using Selected RS Based Indicators. In Remote Sensing-New Challenges of High Resolution, Bochum; Proceedings of the EARSeL Joint Workshop; IEEE: Bochum, Germany, 2008; pp. 5-7.

91. Sutton, P.C.; Costanza, R. Global estimates of market and non-market values derived from nighttime satellite imagery, land cover, and ecosystem service valuation. Ecol. Econ. 2002, 41, $509-527$.

92. Ghosh, T.; Anderson, S.; Powell, R.L.; Sutton, P.C.; Elvidge, C.D. Estimation of Mexico's informal economy and remittances using nighttime imagery. Remote Sens. 2009, 1, 418-444.

93. Ghosh, T.; Powell, R.L.; Anderson, S.; Sutton, P.C.; Elvidge, C.D. Informal economy and remittance estimates of India using nighttime imagery. Int. J. Ecol. Econ. Stat. 2010, 17, 16-50.

94. Henderson, J.V.; Storeygard, A.; Weil, D.N. Measuring Economic Growth from Outer Space; Working Paper No. w15199; National Bureau of Economic Research: Cambridge, MA, USA, 2009.

95. Doll, C.N.; Muller, J.P.; Morley, J.G. Mapping regional economic activity from night-time light satellite imagery. Ecol. Econ. 2006, 57, 75-92.

96. Ma, T.; Zhou, C.; Pei, T.; Haynie, S.; Fan, J. Quantitative estimation of urbanization dynamics using time series of DMSP/OLS nighttime light data: A comparative case study from China's cities. Remote Sens. Environ. 2012, 124, 99-107.

97. Herold, M.; Couclelis, H.; Clarke, K.C. The role of spatial metrics in the analysis and modeling of urban land use change. Comput. Environ. Urban Syst. 2005, 29, 369-399.

98. Seto, K.C.; Shepherd, J.M. Global urban land-use trends and climate impacts. Curr. Opin. Environ. Sustain. 2009, 1, 89-95.

99. Landsberg, H.E. The Urban Climate; Academic Press: New York, NY, USA, 1981; p. 275.

100. Grimm, N.B.; Faeth, S.H.; Golubiewski, N.E.; Redman, C.L.; Wu, J.G.; Bai, X.; Briggs, J.M. Global change and the ecology of cities. Science 2008, 319, 756-760. 
101. Shepherd, J.M.; Stallins, J.A.; Jin, M.; Mote, T.L. Urbanization: Impacts on Clouds, Precipitation, and Lightning. In Urban Ecosystem Ecology (Agronomy Monograph); Aitkenhead-Peterson, J., Volder, A., Eds.; American Society of Agronomy, Crop Science Society of America, Soil Science Society of America: Madison, WI, USA, 2010; p. 354.

102. Hirano, Y.; Yasuoka, Y.; Ichinose, T. Urban climate simulation by incorporating satellite-derived vegetation cover distribution into a Mesoscale Meteorological Model. Theor. Appl. Climatol. 2004, 79, 175-184.

103. Rigo, G.; Parlow, E.; Oesch, D. Validation of satellite observed thermal emission with in-situ measurements over an urban surface. Remote Sens. Environ. 2006, 104, SI 201-SI 210.

104. Hou, P.; Chen, Y.; Qiao, W.; Cao, G.; Jiang, W.; Li, J. Near-surface air temperature retrieval from satellite images and influence by wetlands in urban region. Theor. Appl. Climatol. 2013, $111,109-118$.

105. Weng, Q.; Lu, D.; Liang, B. Urban surface biophysical descriptions and land surface temperature variations. Photogramm. Eng. Remote Sens. 2006, 72, 1275-1286.

106. Nichol, J. Remote Sensing of Urban Areas. In The Sage Handbook of Remote Sensing; Warner, T.A., Ellis, M.D., Foody, G.M., Eds.; Sage Publications: Thousand Oaks, CA, USA, 2009; pp. 423-436.

107. Weng, Q. Thermal infrared remote sensing for urban climate environmental studies: Methods, applications, trends. ISPRS J. Photogramm. Remote Sens. 2009, 64, 335-344.

108. Zhou, H.; Shi, P.; Wang, J.; Yu, D.; Gao, L. Rapid urbanization and implications for river ecological services restoration: Case study in Shenzhen, China. J. Urban Plan. Dev. 2011, 137, $121-132$.

109. Grimm, N.B.; Foster, D.; Groffman, P.; Grove, J.M.; Hopkinson, C.S.; Nadelhoffer, K.J.; Pataki, D.E.; Peters, D.P.C. The changing landscape: Ecosystem responses to urbanization and pollution across climatic and societal gradients. Front. Ecol. Environ. 2008, 6, 264-272.

110. Rosenzweig, C.; Solecki, W.D.; Parshall, L.; Lynn, B.; Cox, J.; Goldberg, R.; Hodges, S.; Gaffin, S.; Slosberg, R.B.; Savio, P.; et al. Mitigating New York city's heat island. Bull. Am. Meteorol. Soc. 2009, 90, 1297-1312.

111. Chapin, F.S.; Carpenter, S.R.; Kofinas, G.P.; Folke, C.; Abel, N.; Clark, W.C.; Olsson, P.; Smith, D.M.S.; Walker, B.; Young, O.R.; et al. Ecosystem stewardship: Sustainability strategies for a rapidly changing planet. Trends Ecol. Evol. 2010, 25, 241-249.

112. Schmid, H.P.; Cleugh, H.A.; Grimmond, C.S.B.; Oke, T.R. Spatial variability of energy fluxes in suburban terrain. Bound.-Layer Meteorol. 1991, 54, 249-276.

113. Shepherd, J.M. A review of current investigations of urban-induced rainfall and recommendations for the future. Earth Interact. 2005, 9, 1-27.

114. Liu, H.; Weng, Q. Scaling effect on the relationship between landscape pattern and land surface temperature: A case study of Indianapolis, United States. Photogramm. Eng. Remote Sens. 2009, 75, 291-304.

115. Zhan, W.F.; Chen, Y.H.; Zhou, J.; Wang, J.F.; Liu, W.Y.; Voogt, J.; Zhu, X.L.; Quan, J.L.; Li, J. Disaggregation of remotely sensed land surface temperature: Literature survey, taxonomy, issues, and caveats. Remote Sens. Environ. 2013, 131, 119-139. 
116. Nichol, J. Remote sensing of urban heat islands by day and night. Photogramm. Eng. Remote Sens. 2005, 71, 613-621.

117. Balling, R.C.; Brazel, S.W. High-resolution surface-temperature patterns in a complex urban terrain. Photogramm. Eng. Remote Sens. 1998, 54, 1289-1293.

118. Dousset, B.; Gourmelon, F.; Laaidi, K.; Zeghnoun, A.; Giraudet, E.; Bretin, P.; Mauri, E.; Vandentorren, S. Satellite monitoring of summer heat waves in the Paris metropolitan area. Int. J. Climatol. 2011, 31, 313-323.

119. Rosenfeld, D.; Lensky, I.M. Satellite-based insights into precipitation formation processes in continental and maritime convective clouds. Bull. Am. Meteorol. Soc. 1998, 79, 2457-2476.

120. Ashley, W.S.; Bentley, M.L.; Stallins, J.A. Urban induced thunderstorm modification in the Southeast United States. Clim. Chang. 2012, 113, 481-498.

121. Shepherd, J.M.; Pierce, H.; Negri, A.J. Rainfall modification by major urban areas: Observations from spaceborne rain radar on the TRMM satellite. J. Appl. Meteorol. 2002, 41, 689-701.

122. Muller, C.L.; Kidd, C.; Fairchild, I.J.; Baker, A. Investigation into clouds and precipitation over an urban area using micro rain radars, satellite remote sensing and fluorescence spectrophotometry. Atmos. Res. 2010, 96, 241-255.

123. Srivastava, S.; Lal, S.; Subrahamanyam, D.B.; Gupta, S.; Venkataramani, S.; Rajesh, T.A. Seasonal variability in mixed layer height and its impact on trace gas distribution over a tropical urban site: Ahmedabad. Atmos. Res. 2010, 96, 79-87.

124. Jacobson, M.; Delucchi, M. Providing all global energy with wind, water, and solar power, Part I: Technologies, energy resources, quantities and areas of infrastructure, and materials. Energy Policy 2011, 39, 1154-1169.

125. Han, Y.; Lau, S.L.; Kayhanian, M.; Stenstrom, M.K. Characteristics of highway stormwater runoff. Water Environ. Res. 2006, 78, 2377-2388.

126. Wu, C.; Murray, A. Estimating impervious surface distribution by spectral mixture analysis. Remote Sens. Environ. 2003, 84, 493-505.

127. Matsushita, B.; Fukushima, T. Methods for retrieving hydrologically significant surface parameters from remote sensing: A review for applications to East Asia region. Hydrol. Process. 2009, 533, 524-533.

128. Durga Rao, K.H.V. Multi-criteria spatial decision analysis for forecasting urban water requirements: A case study of Dehradun city, India. Landsc. Urban Plan. 2005, 71, 163-174.

129. Machault, V.; Vignolles, C.; Borchi, F.; Vounatsou, P.; Pages, F.; Briolant, S.; Lacaux, J.; Rogier, C. The use of remotely sensed environmental data in the study of Malaria. Geospat. Health 2011, 5, 151-168.

130. Adriaens, P.; Skerlos, S.; Edwards, E.A.; Goovaerts, P.; Egli, T. Intelligent infrastructure for sustainable potable water supplies: A roundtable for emerging transnational research and technology development needs. Biotechnol. Adv. 2003, 22, 119-134.

131. He, H.; Zhou, J.; Wu, Y.; Zhang, W.; Xie, X. Modeling the interaction of urbanization and surface water quality environment. Environ. Forensics 2008, 9, 215-225.

132. Coskun, H.G. Remote sensing and GIS techniques for temporal evaluation of environmental impacts on major drinking water dam and Basin of Metropolis Istanbul. Fresenius Environ. Bull. 2009, 18, 261-269. 
133. Ulugtekin, N.; Balcik, F.B.; Dogru, A.O.; Goksel, C.; Alaton, I.A.; Orhon, D. The use of remote sensing and geographic information systems for the evaluation of river basins: A case study for Turkey, Marmara River Basin and Istanbul. J. Environ. Sci. Health Part A Toxic Hazard. Subst. Environ. Eng. 2009, 44, 388-396.

134. Musaoglu, N.; Tanik, A.; Kocabas, V. Identification of land-cover changes through image processing and associated impacts on water reservoir conditions. Environ. Manag. 2005, 35, $220-230$.

135. Kucukmehmetoglu, M.; Geymen, A. Measuring the spatial impacts of urbanization on the surface water resource basins in Istanbul via remote sensing. Environ. Monit. Assess. 2008, 142, 153-169.

136. Oki, K.; Yasuoka, Y. Mapping the potential annual total nitrogen load in the river basins of Japan with remotely sensed imagery. Remote Sens. Environ. 2008, 112, 3091-3098.

137. Hellweger, F.L.; Miller, W.; Oshodi, K.S. Mapping turbidity in the Charles River, Boston using a high resolution satellite. Environ. Monit. Assess. 2007, 132, 311-320.

138. Carlson, T.N. Applications of remote sensing to urban problems. Remote Sens. Environ. 2003, 86, 273-274.

139. Lin, Y.P.; Lin, Y.B.; Wang, Y.T.; Hong, N.M. Monitoring and predicting land use changes and the hydrology of the urbanized Paochiao Watershed in Taiwan using remote sensing data, urban growth models and a hydrological model. Sensors 2008, 8, 658-680.

140. Chabaeva, A.; Civco, D.A.; Hurd, J.D. Assessment of impervious surface estimation techniques. ASCE J. Hydrol. Eng. 2009, 14, 377-387.

141. Morgan, K.M.; Newland, L.W.; Weber, E.; Busbey, A.B. Using SPOT satellite data to map impervious cover for urban runoff predictions. Toxicol. Environ. Chem. 1993, 40, 11-16.

142. Kepner, W.G.; Semmens, D.J.; Bassett, S.D.; Mouat, D.A.; Goodrich, D.C. Scenario analysis for the San Pedro River, analyzing hydrological consequences of a future environment. Environ. Monit. Assess. 2004, 94, 115-127.

143. Thanapura, P.; Helder, D.L.; Burckhard, S.; Warmath, E.; O’Neill, M.; Galster, D.H. Mapping urban land cover using QuickBird NDVI image and GIS spatial modeling for runoff coefficient determination. Photogramm. Eng. Remote Sens. 2007, 73, 57-65.

144. Ackerman, D.; Stein, E.D. Estimating the variability and confidence of land use and imperviousness relationships at a regional scale. J. Am. Water Resour. Assoc. 2008, 44, 996-1008.

145. Jat, M.K.; Khare, D.; Garg, P.K.; Shankar, V. Remote sensing and GIS-based assessment of urbanization and degradation of watershed health. Urban Water J. 2009, 6, 251-263.

146. Rekha, V.B.; Thomas, A.P.; Suma, M.; Vijith, H. An integration of spatial information technology for groundwater potential and quality investigations in Koduvan Ár Sub-Watershed of Meenachil River Basin, Kerala, India. J. Indian Soc. Remote Sens. 2011, 39, 63-71.

147. Dujardin, J.; Batelaan, O.; Canters, F.; Boel, S.; Anibas, C.; Bronders, J. Improving surface-subsurface water budgeting using high resolution satellite imagery applied on a brownfield. Sci. Total Environ. 2011, 409, 800-809.

148. Sanders, B.F.; Schubert, J.E.; Gallegos, H.A. Integral formulation of shallow-water equations with anisotropic porosity for urban flood modeling. J. Hydrol. 2008, 362, 19-38. 
149. Shahapure, S.S.; Eldho, T.I.; Rao, E.P. Coastal urban flood simulation using FEM, GIS and remote sensing. Water Resour. Manag. 2010, 24, 3615-3640.

150. Reistetter, J.A.; Russell, M. High-resolution land cover datasets, composite curve numbers, and storm water retention in the Tampa Bay, FL region. Appl. Geogr. 2011, 31, 740-747.

151. Niebergall, S.; Loew, A.; Mauser, W. Object-Oriented Analysis of very High-Resolution Quickbird Data for Megacity Research in Delhi/India. In Proceedings of the 2007 Urban Remote Sensing Joint Event, Paris, France, 11-13 April 2007.

152. Schumacher, J.; Luedeling, E.; Gebauer, J.; Saied, A.; El-Siddig, K.; Buerkert, A. Spatial expansion and water requirements of urban agriculture in Khartoum, Sudan. J. Arid Environ. 2009, 73, 399-406.

153. Endter-Wada, J.; Kurtzman, J.; Keenan, S.P.; Kjelgren, R.K.; Neale, C.M. Situational waste in landscape watering: Residential and business water use in an urban Utah community 1. J. Am. Water Resour. Assoc. 2008, 44, 902-920.

154. Brown, D.G.; Johnson, K.M.; Loveland, T.R.; Theobald, D.M. Rural land-use trends in the conterminous United States, 1950-2000. Ecol. Appl. 2005, 15, 1851-1863.

155. Agarwal, C.; Green G.M.; Grove J.M.; Evans, T.; Schweik, C. A Review and Assessment of Land-Use Change Models: Dynamics of Space, Time, and Human Choice; Joint Publication by the Center for the Study of Institutions, Population, and Environmental Change at Indiana University-Bloomington and the USDA Forest Service; USDA Forest Service Northeastern Forest Research Station: Burlington, VT, USA, 2002.

156. Herold, M.; Liu, X.; Clarke, K.C. Spatial metrics and image texture for mapping urban land use. Photogramm. Eng. Remote Sens. 2003, 69, 991-1001.

157. Fragkias, M.; Seto, K.C. Modeling urban growth in data-sparse environments: A new approach. Environ. Plan. B 2007, 34, 858-883.

158. Beck, L.R.; Lobitz, B.M.; Wood, B.L. Remote sensing and human health: New sensors and new opportunities. Emerg. Infect. Dis. 2000, 6, 217-227.

159. Liu, H.; Weng, Q. An examination of the effect of landscape pattern, land surface temperature, and socioeconomic conditions on WNV dissemination in Chicago. Environ. Monit. Assess. 2009, $159,143-161$.

160. Frank, L.D.; Andresen, M.A.; Schmid, T.L. Obesity relationships with community design, physical activity, and time spent in cars. Am. J. Prev. Med. 2004, 27, 87-96.

161. Chen, X.; Nordhaus, W.D. Using luminosity data as a proxy for economic statistics. Proc. Natl. Acad. Sci. USA 2011, 108, 8589-8594.

162. NASA. Available online: http://hyspiri.jpl.nasa.gov/ (accessed on 24 April 2014).

163. Leung, D; Newsam, S. Exploring geotagged images for land-use classification. In Proceedings of the ACM International Conference on Multimedia: Workshop on Geotagging and Its Applications in Multimedia, Nara, Japan, 29 October-2 November 2012.

(C) 2014 by the authors; licensee MDPI, Basel, Switzerland. This article is an open access article distributed under the terms and conditions of the Creative Commons Attribution license (http://creativecommons.org/licenses/by/3.0/). 